Review Article

\title{
Cardiac Tamponade Caused by Cutibacterium acnes: An Updated and Comprehensive Review of the Literature
}

\author{
Ghina Fakhri $\mathbb{D}^{1},{ }^{1}$ Christelle Tayeh, ${ }^{1}$ Ghassan Dbaibo ${ }^{(D)},{ }^{2}$ Omar El Sedawy, \\ Nour Abdul Halim, ${ }^{1}$ Fadi Bitar $\left(\mathbb{0},{ }^{1}\right.$ and Mariam Arabi ${ }^{1}{ }^{1}$ \\ ${ }^{1}$ Division of Cardiology, Department of Pediatrics and Adolescent Medicine, American University of Beirut Medical Center, \\ Beirut, Lebanon \\ ${ }^{2}$ Division of Infectious Diseases, Department of Pediatrics and Adolescent Medicine, \\ American University of Beirut Medical Center, Beirut, Lebanon
}

Correspondence should be addressed to Mariam Arabi; ma81@aub.edu.lb

Received 29 January 2020; Revised 26 May 2020; Accepted 12 June 2020; Published 15 July 2020

Academic Editor: Mario Dell'Agli

Copyright (C) 2020 Ghina Fakhri et al. This is an open access article distributed under the Creative Commons Attribution License, which permits unrestricted use, distribution, and reproduction in any medium, provided the original work is properly cited.

\begin{abstract}
Bacterial pericarditis is a critical diagnosis caused by a wide range of organisms including Streptococcus pneumoniae and other anaerobic organisms like Cutibacterium acnes which has been gaining more importance as a causative organism. Cutibacterium species are Gram-positive microaerophilic rods that constitute part of the normal flora of skin and mucosal membranes. The incidence of pericarditis caused by this organism is underreported as it is often dismissed as a skin flora contaminant. However, if left untreated, Cutibacterium acnes can cause pericarditis with serious complications. In this paper, we present a comprehensive review of the literature regarding pericarditis caused by Cutibacterium acnes along with a case presentation from our institution. In our institution, a 20-year-old man with history of atrial septal defect presented with chest pain radiating to the back along with symptoms of upper respiratory tract infection including headaches and myalgia. Electrocardiogram was remarkable for diffuse low-voltage waves. Echocardiography revealed a large pericardial effusion with tamponade features. Pericardiocentesis drained $1.2 \mathrm{~L}$ of milky fluid. Pericardial fluid analysis grew Cutibacterium acnes after being cultured for 8 days. The patient received 3 weeks of IV penicillin followed by 3 weeks of oral amoxicillin along with nonsteroidal anti-inflammatory agents and colchicine with no recurrence. Pericarditis caused by Cutibacterium acnes requires a high clinical suspicion since isolation of this organism can be dismissed as a skin flora contaminant. Literature review reveals that this infection may be underdiagnosed and underreported. Prompt diagnosis may lead to timely initiation of antibiotics which can help prevent devastating complications like constrictive pericarditis. Prospective studies are needed to evaluate the true incidence and prevalence of this disease.
\end{abstract}

\section{Introduction}

Infectious pericarditis remains a very critical diagnosis, and many infectious organisms can be the culprits. Bacterial pericarditis is a subset of infectious pericarditis that is an important cause of morbidity and mortality as it progresses rapidly and is fatal if left untreated $[1,2]$. In the current era of modern antibacterial therapy, the incidence of bacterial pericarditis decreased to 1 in 18,000 individuals [3-5]. Moreover, there has been a change in the spectrum of pathogens responsible for bacterial pericarditis. Around the time of World War II, the pathogens consisted of Gram- positive organisms and has transitioned to include Gramnegative as well as anaerobic ones. Keeping a high index of suspicion is crucial to avoid diagnostic delay and initiate proper treatment, as there are numerous critical complications such as constrictive pericarditis, tamponade, and left ventricular pseudoaneurysm $[3,4,6]$. Early detection is crucial to allow timely initiation of the appropriate antibacterial treatment, which, if administered early, can prevent these complications.

The usual organism responsible for pericarditis in the preantibiotic era was Streptococcus pneumoniae and was soon followed by facultative aerobic Gram-negative bacilli 
including Escherichia coli and Klebsiella pneumoniae. Recently, the spectrum has shifted to include anaerobic bacteria such as Prevotella, Bacteroides fragilis, and Peptostreptococcus species and other rare organisms like Cutibacterium acnes (C. acnes) [6]. C. acnes is considered to have a low virulence but has been recognized recently as a cause of serious infections like endocarditis and pericarditis $[7,8]$. The incidence of pericarditis caused by $C$. acnes has been increasing worldwide with scarce literature reported on the matter. C. acnes is a slowly growing Gram-positive microaerophilic rod that requires no less than 7 days to grow in culture. In this manuscript, we report Cutibacterium acnes infection in an adult with pericarditis and present an updated comprehensive review of $C$. acnes causing pericarditis.

\section{Methodology}

This review was finalized in December 2019. The literature review is up to date and articles were critically appraised for validity and relevance. A comprehensive search was conducted in PubMed, Medline (1946-2018), and Google Scholar for the presence of grey literature. Articles were included if they were published in the English language and reported on the incidence or prevalence of Cutibacterium acnes in patients with pericardial effusion or pericarditis. No limitations were made on year of publication, age, or country of origin. The search strategy consisted of two concepts. The first concept regarding Cutibacterium acnes was searched using MeSH terms and keywords for the following: Propionibacterium acnes, Cutibacterium acnes, Propionibacterium, cutibacterium, $\mathrm{C}$ Acnes, and $\mathrm{P}$ acnes. As for the second concept, it was searched using the following $\mathrm{MeSH}$ terms and keywords: pericardial effusion, effusion, pericarditis, and tamponade. A total of 6 articles reported on $10 \mathrm{Cuti-}$ bacterium acnes cases and their association with pericarditis. A table summarizing their characteristics is available (Table 1).

\section{Case Presentation}

A 20-year-old man, with a history of pulmonary stenosis and atrial septal defect (ASD) status post-ASD closure, presented with respiratory tract infection symptoms, myalgia, chest pain radiating to the back, and headache of two weeks duration. In addition, he reported nasal congestion, dyspnea, and a nonproductive cough. He did not have rhinorrhea, sneezing, fever, or any other sign or symptom. Physical exam and vital signs were remarkable for few abnormalities. Temperature taken from the axilla was $36.9^{\circ} \mathrm{C}$, oxygen saturation was $94 \%$, pulse was 97 beats per minute, respiratory rate per minute was 18 , and blood pressure was $143 /$ $84 \mathrm{mmHg}$. The physical exam was pertinent for distant heart sounds and a grade II/VI systolic ejection murmur without friction rub. In addition, he was noted to have few comedones on his upper back that were not inflamed or infected in nature and have been present for a long time and left untreated. Electrocardiogram (EKG) revealed low voltage waves (Figure 1). Transthoracic electrocardiogram revealed mild-to-moderate pulmonary stenosis and a large pericardial effusion with right ventricular collapse suggestive of tamponade (Figure 2). Chest X-ray revealed increased cardiac silhouette, and this was followed up with a CT of the chest without contrast which revealed a moderate-to-large pericardial effusion with maximal thickness up to $3.2 \mathrm{~cm}$ inferiorly and established the diagnosis of pericarditis (Figure 3). Complete blood count revealed leukocytosis (WBC count: 15,100/cu.mm), with 67\% neutrophilia. Blood culture, on the other hand, revealed no growth. A full PCR respiratory panel performed upon presentation, of 22 pathogenic agents (nucleic acid from Adenovirus, Coronavirus, Rhinovirus, Enterovirus, Human Metapneumovirus, Middle East Respiratory Syndrome Coronavirus, Parainfluenza virus, Respiratory Syncytial virus, Bordetella pertussis, Chlamydia pneumoniae, and $M y$ coplasma pneumoniae) was negative as well. Initially, erythrocyte sedimentation rate was $8 \mathrm{~mm} /$ hour and C-reactive protein was $5.3 \mathrm{mg} / \mathrm{L}$. Empirically, the patient was started on Ibuprofen $400 \mathrm{mg}$ three times daily. To alleviate the right ventricular collapse, immediate drainage was undertaken. Pericardiocentesis was performed draining $1.2 \mathrm{~L}$ of a milky fluid. The fluid analysis revealed the following: WBC cell count $63 / \mathrm{cu} . \mathrm{mm}$ with many macrophages on microscopy, LDH $348 \mathrm{IU} / \mathrm{L}$, protein $71.7 \mathrm{~g} / \mathrm{L}$, glucose $20 \mathrm{mg} / \mathrm{dL}$, and albumin $48.9 \mathrm{~g} / \mathrm{L}$. A work-up looking for the rheumatological diseases was done and was negative (ANA, rheumatoid factor, anti-CCP2, anti-centromere antibodies, antiScl70 antibodies, anti-smith antibodies, and anti-ds DNA antibodies). Cardiac markers including troponin, creatine phosphokinase, and CK-MB were checked and were negative. Fluid testing for mycobacterium tuberculosis, fungi, and other bacteria was negative. After the drainage, the patient was switched to ketoprofen $100 \mathrm{mg}$ twice daily as well as colchicine $1 \mathrm{mg}$ once daily as part of the standard of care for patients with pericardial effusion. The treatment with colchicine and ketoprofen lasted for a total of 3 months. After 8 days of incubation, the fluid culture revealed moderate growth of Cutibacterium acnes. As such, the patient received 3 weeks of parenteral penicillin G. Follow-up echocardiography revealed a residual rim of pericardial effusion. The patient was given 3 more weeks of oral amoxicillin. His last follow-up at the end of the antibiotic course showed complete resolution of his symptoms and disappearance of the residual pericardial effusion. Repeat EKG revealed normalization of the voltage on all the leads (Figure 4). Vital signs returned to baseline. Heart rate was 80 , blood pressure was $125 / 74 \mathrm{mmHg}$, and oxygen saturation was $100 \%$. The ketoprofen and colchicine were discontinued after complete resolution of the effusion. The repeat CRP on two separate occasions was normal $(<2.5 \mathrm{mg} /$ L). He did not require a continuous pericardial drain nor surgical intervention.

\section{Discussion}

4.1. Incidence and Etiology. Bacterial pericarditis has become a rare entity in our era where the incidence decreased from $1 / 254$ to $1 / 18,000$ persons, attributed to the widespread use 
TABLE 1: Summary characteristics of patients with pericarditis caused by Cutibacterium acnes.

\begin{tabular}{|c|c|c|c|c|c|c|c|}
\hline $\begin{array}{l}\text { Author } \\
\text { (year) }\end{array}$ & $\begin{array}{l}\text { Sex, } \\
\text { age }\end{array}$ & Medical history & $\begin{array}{l}\text { Diagnostic } \\
\text { delay }\end{array}$ & $\begin{array}{c}\text { Echocardiography } \\
\text { results }\end{array}$ & Medical treatment, duration & Surgical treatment & Outcome \\
\hline $\begin{array}{l}\text { Iseki } \\
(1998)[9]\end{array}$ & $\begin{array}{l}\mathrm{M} \\
62\end{array}$ & $\begin{array}{l}\text { Hepatitis } B \text {, } \\
\text { tooth decay }\end{array}$ & 3 months & $\begin{array}{l}\text { Constrictive } \\
\text { pericarditis }\end{array}$ & None & $\begin{array}{c}\text { Total } \\
\text { pericardiectomy }\end{array}$ & Resolved \\
\hline $\begin{array}{l}\text { Parikh } \\
(2009) \\
{[10]}\end{array}$ & F, 46 & $\begin{array}{l}\text { Hepatitis C, } \\
\text { tooth decay, } \\
\text { substance abuse }\end{array}$ & NA & Tamponade & Pen G-7 w & Pericardial window & Resolved \\
\hline \multirow{5}{*}{$\begin{array}{l}\text { Mesado } \\
\text { et al. } \\
(2013) \\
{[11]}\end{array}$} & $\begin{array}{l}M \\
55\end{array}$ & $\begin{array}{l}\text { Respiratory tract } \\
\text { infection }\end{array}$ & 2 months & $\begin{array}{l}\text { Constrictive } \\
\text { pericarditis }\end{array}$ & $\begin{array}{c}\text { Cef + AC: } 1 \mathrm{~m} ; \\
\text { Amox + steroids: } 6 \mathrm{~m}\end{array}$ & $\begin{array}{l}\text { Subtotal } \\
\text { pericardiectomy }\end{array}$ & $\begin{array}{l}1 \text { relapse, } \\
\text { resolved in } \\
1 \text { year }\end{array}$ \\
\hline & $\begin{array}{l}M \\
26\end{array}$ & Dental caries & 2 weeks & Tamponade & $\begin{array}{c}\text { AC: } 6 \mathrm{~m} \text {; } \\
\text { Dox: } 2 \mathrm{~m} \\
\text { Steroids: } 3 \mathrm{~m}\end{array}$ & \multirow{4}{*}{$\begin{array}{c}\text { Pericardial window } \\
\text { surgical drainage } \\
\text { Subtotal } \\
\text { pericardiectomy, } \\
\text { patched } \\
\text { epicardiectomy } \\
\text { Total } \\
\text { pericardiectomy } \\
\text { Subxiphoid } \\
\text { pericardial } \\
\text { drainage }\end{array}$} & $\begin{array}{l}1 \text { relapse, } \\
\text { resolved in } \\
21 \mathrm{~m}\end{array}$ \\
\hline & $\begin{array}{l}\mathrm{M}, \\
31\end{array}$ & Dental infection & 9 months & $\begin{array}{l}\text { Constrictive } \\
\text { pericarditis }\end{array}$ & $\begin{array}{c}\text { Pen G + Amox: } 10 \mathrm{~m} \text {; } \\
\text { Mox: } 8 \mathrm{~m} \text {; } \\
\text { Steroids + NSAIDs + colchicine: } \\
10 \mathrm{~m}\end{array}$ & & $\begin{array}{l}\text { Resolved } \\
\text { at } 3 y\end{array}$ \\
\hline & $\begin{array}{l}\mathrm{M}, \\
72\end{array}$ & NA & 20 months & $\begin{array}{l}\text { Pericardial } \\
\text { thickening }\end{array}$ & $\begin{array}{c}\text { Cef: } 2 \mathrm{w} \\
\text { Minocycline: } 2 \mathrm{~m}\end{array}$ & & Resolved \\
\hline & F, 38 & $\begin{array}{l}\text { Respiratory tract } \\
\text { infection }\end{array}$ & 1 month & $\begin{array}{l}\text { Constrictive } \\
\text { pericarditis }\end{array}$ & $\begin{array}{l}\text { Cef + deptomycin: } 2 \mathrm{w} \\
\text { Dox: } 6 \mathrm{~m}\end{array}$ & & 2 relapses \\
\hline $\begin{array}{l}\text { Cruz } \\
\text { et al. } \\
(2015) \\
{[12]}\end{array}$ & $\begin{array}{l}M \\
61\end{array}$ & $\begin{array}{c}\text { Coronary artery } \\
\text { disease }\end{array}$ & 5 months & $\begin{array}{l}\text { Constrictive } \\
\text { pericarditis }\end{array}$ & $\begin{array}{c}\text { Amox: } 3 \mathrm{w} \\
\text { PenG + colchicine }+ \text { Dox: } 6 \mathrm{w}\end{array}$ & None & $\begin{array}{l}1 \text { relapse, } \\
\text { resolved in } \\
10 \mathrm{w}\end{array}$ \\
\hline $\begin{array}{l}\text { Jensen } \\
(2017)\end{array}$ & $\begin{array}{l}\mathrm{M}, \\
75\end{array}$ & $\begin{array}{l}\text { Hypertension, } \\
\text { heart failure }\end{array}$ & 2 months & $\begin{array}{l}\text { Concentric } \\
\text { pericarditis }\end{array}$ & Pen G: $4 \mathrm{w} ; \mathrm{AC}+$ NSAIDs: $12 \mathrm{w}$ & $\begin{array}{c}\text { Subtotal } \\
\text { pericardiectomy }\end{array}$ & Resolved \\
\hline $\begin{array}{l}\text { Farhat } \\
(2018) \\
{[2]}\end{array}$ & $\begin{array}{l}\mathrm{M}, \\
71\end{array}$ & NA & 3 weeks & Tamponade & Vancomycin: $2 \mathrm{w}$ & $\begin{array}{l}\text { Subxiphoid } \\
\text { pericardial } \\
\text { drainage }\end{array}$ & Resolved \\
\hline $\begin{array}{l}\text { Arabi } \\
(2019)\end{array}$ & $\begin{array}{l}M \\
20\end{array}$ & ASD & 2 weeks & Tamponade & $\begin{array}{l}\text { Pen G: } 3 \mathrm{w} \\
\text { Amox: } 3 \mathrm{w}\end{array}$ & None & Resolved \\
\hline
\end{tabular}

Amox: amoxicillin; AC: amoxicillin-clavulanic acid; ASD : atrial septal defect; Cef: ceftriaxone; Dox: doxycycline; Mox: moxifloxacin; NA : not available; NSAIDs: nonsteroidal anti-inflammatory agents; Pen: penicillin.

of antibiotics [3-5]. Early on, Staphylococcus and Streptococcus were very common, followed by Haemophilus and Mycobacterium tuberculosis. Bacterial pericarditis has recently witnessed an increased incidence of anaerobic infections from Prevotella species and Cutibacterium acnes reaching $40 \%$ of all cases $[3,4]$. Cutibacterium species are vital members of the normal microbial flora which reside in the pilosebaceous follicles in the human skin, conjunctiva, oral cavity, external ear, and intestinal tract $[13,14]$. C. acnes is commonly dismissed as a skin flora organism, but it has been associated with serious infections of the skin, soft tissue, cardiovascular system, and other implant-associated infections. C. acnes infection of the skin is acquired in the following manner: inflammatory mediators released into the skin trigger an inflammatory state, altered keratinization process, comedone formation, increased androgens, sebum production, and, finally, colonization of the follicle. This pathogen has the ability to trigger an inflammatory cytokine release in macrophages thereby modulating the immune state. The optimal environment for C. acnes is provided by the skin's anaerobic and lipidic conditions. There are a number of virulence factors produced by this organism such as the ability to cause bacterial seeding, manipulation of host immune system, and biofilm formation, all of which contribute to disease evolvement. In patients who undergo dental or other surgeries, C. acnes can cause seeding and deep bacterial infection $[15,16]$. This organism is a Grampositive, catalase-positive microaerophilic anaerobic-aerotolerant pleomorphic bacillus. It has an ability to form biofilms on many devices and to survive up to 8 months in anaerobic conditions or human tissue with low oxidation status $[10,17]$. Recovering $C$. acnes from blood, fluid, or tissue cultures may be difficult as it requires 7 to 14 days for proper isolation. Moreover, the culture time might extend to 3 weeks in both aerobic and anaerobic atmospheres to grow C. acnes $[17,18]$. C. acnes has a solid reputation for being both slow growing and of low virulence, but there have been recent emerging reports on its involvement in periodontitis, pericarditis, endocarditis, as well as infections in the central nervous system, and prosthetic devices $[3,4,19]$. It can be considered a major contaminant, but physicians should not dismiss repeated isolation of $C$. acnes. In addition, microscopic examination of tissue infected with $C$. acnes reveal inflammatory infiltration and fibrosis which further 


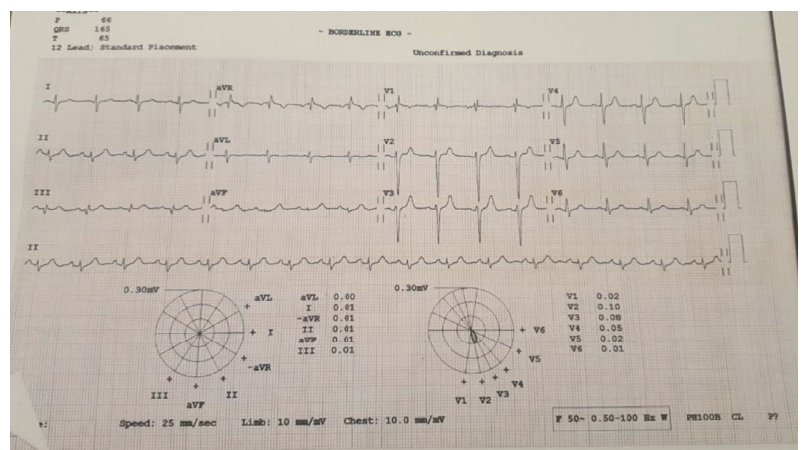

FIGURE 1: Electrocardiogram showing low voltage among the majority of the leads.

confirms that $C$. acnes has an immunostimulatory effect on the mononuclear phagocyte system $[11,16]$. A comprehensive literature review revealed 61 cases of pericarditis caused by $C$. acnes of which only 10 had supportive demographic or clinical information presented in Table 1 [1]. Patients diagnosed with $C$. acnes-induced pericarditis are usually adults with a mean age of 50.6 years. Our patient has been the youngest of all patients diagnosed with pericarditis caused by $C$. acnes.

4.2. Risk Factors. Bacterial pericarditis has always been considered as a complication to pneumococcal pneumonia in the old era, but, currently, most cases are associated with compromised immunity, cardiac surgery, and malignancy, among others [20-23]. The pericardium, unlike other organs, is considered a rare primary site of infection and there are four different ways believed to aid in spreading the infection: (1) local extension such as endocarditis, (2) direct extension of an intrathoracic process such as pneumonia, (3) perforating injury to the chest wall, and (4) hematogenous spread $[3,4,6,12,13]$. The frequency of an underlying bacteremia depends on several factors such as the host's immune system, skin colonization by C. acnes, presence of dental caries, or infections. In addition, there are sites in the human body where C. acnes colonization is heavier than others. For example, areas of the under arm and around the shoulder carry a higher infection risk and higher likelihood of bacteremia if the patient goes into surgery than sites of the hip. That is the case because there are more sebaceous glands around the shoulder area than there are around the hip which increases the chance for bacterial seeding and subsequent infection [24]. The frequency of C. acnes bacteremia is reported in $10 \%$ of periprosthetic joint infection with a higher predilection for shoulder surgeries. The other famous sites of infection include breast implants and cardiac sites especially the valves. In a large study, authors identified 24 out of $1325(1.8 \%)$ patients with infective endocarditis to have had C. acnes positive culture. Of those patients, C. acnes blood culture was positive in only $12.5 \%$ of them [25-27]. In a study of 166 patients whose blood cultures yielded anaerobic bacteria, authors found that none of the 53 patients with Cutibacterium bacteremia had clinically significant disease [25]. In another study, the incidence of clinically

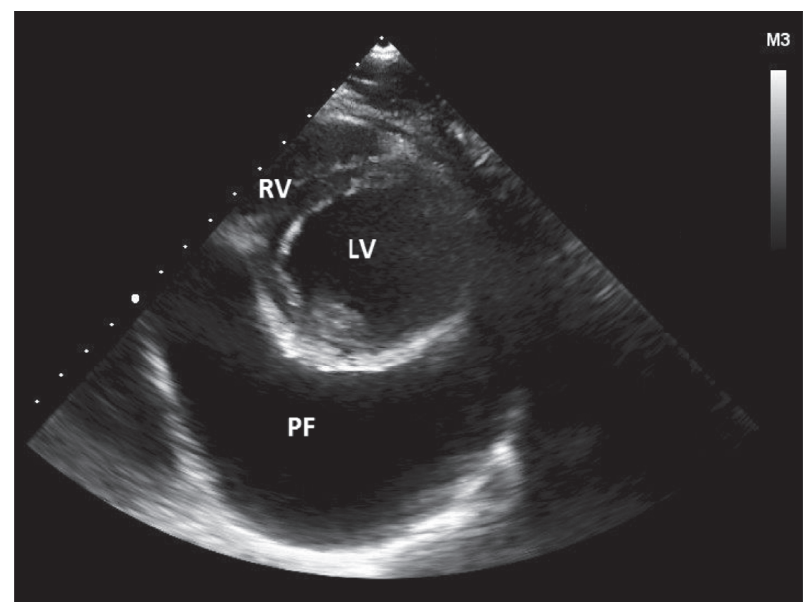

FIGURE 2: Echocardiography, short-axis view of the heart showing the LV and large pericardial effusion. LV: left ventricle; PF: pericardial fluid; RV: right ventricle.

significant $C$. acnes bacteremia was reported to be $3.5 \%$ but none of their patients had pericarditis [24].

In our patient, we do not believe that his infection started as a serious one. Despite the dyspnea, he was able to ambulate and breathe comfortably. He had stable vital signs and was admitted to the regular hospital ward without the need for respiratory support or intensive care. We reached the conclusion that his symptoms were not solely caused by a respiratory infection since he had scarce upper URI symptoms, respiratory panel was negative, and chest X-ray or CT did not reveal a pulmonary infection. As such, we believe that the symptoms were arising from the pericarditis instead of a respiratory infection.

Moreover, certain conditions increase the likelihood of acquiring C. acnes such as chest wall trauma, tooth decay and dental surgeries, immunosuppression, cardiac surgery, prosthetic heart valves, ventriculoperitoneal shunts, and other foreign bodies $[8,9,18,28-30]$. While our patient had comedonal acne, he did not suffer from other skin infections, dental caries, or abscesses.

4.3. Clinical Presentation. Commonly, bacterial pericarditis presents with high-grade fever, chills, shortness of breath, and tachycardia. A high index of suspicion is required because the classic signs of pleuritic chest pain, pericardial friction rub, and electrical alternans are commonly absent. Physicians need to have a high index of suspicion as the classic signs and symptoms of pleuritic chest pain, electrical alternans, and pericardial friction rub may be absent, but fever is almost always present. Early hemodynamic compromise such as tamponade may be indicated by hypotension $[6,20]$. Unfortunately, some patients may present with fever and hypotension only and such a presentation can be misdiagnosed as a septic shock and delay the diagnosis and treatment.

4.4. Diagnosis. General laboratory tests may be nonspecific in patients with bacterial pericarditis but anemia and leukocytosis with a left shift are commonly present in addition 


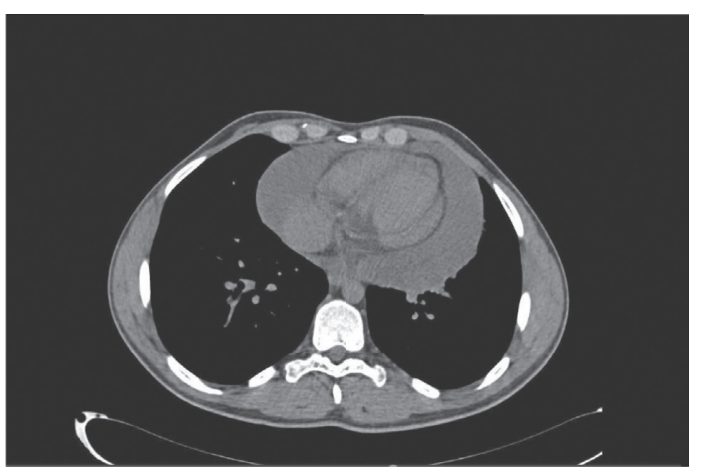

(a)

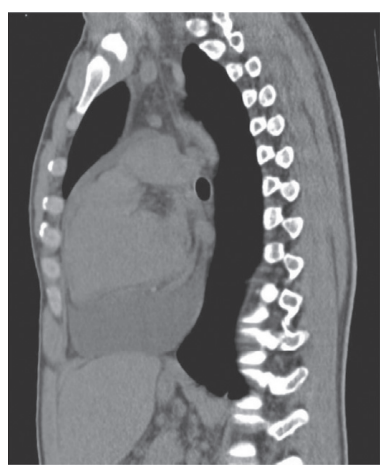

(b)

Figure 3: Axial (a) and coronal (b) sections of a nonenhanced CT chest showing pericardial effusion.

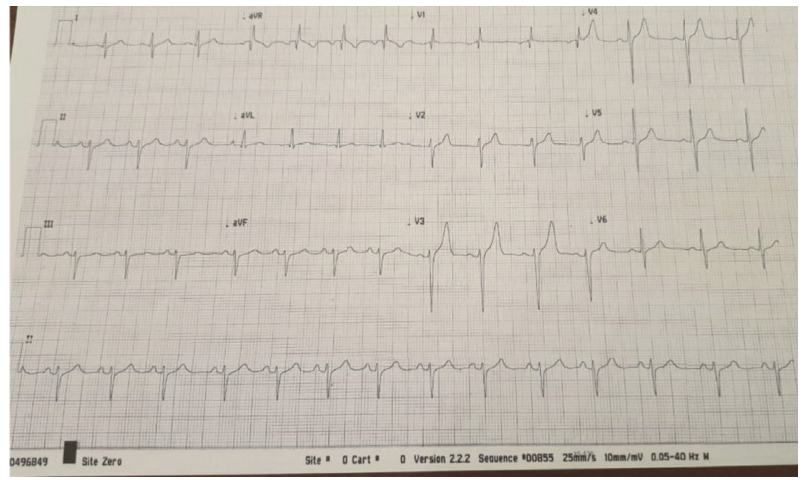

FIGURE 4: Electrocardiogram after treatment for pericardial effusion revealing normalization of the voltage in the majority of the leads.

to increased ESR and CRP $[6,20]$. The pauci-inflammatory nature of $C$. acnes may have contributed to the lower-thanexpected rise in inflammatory markers in our patient. Chest $\mathrm{X}$-ray might reveal cardiomegaly, pleural effusion, pulmonary infiltrates, or mediastinal widening. On EKG, diffuse ST elevation and $\mathrm{PR}$ depression may only occasionally be present $[2-6,31]$. Although TTE cannot distinguish between inflammatory effusions and purulent fluid collections, it can facilitate the detection and quantification of fluid. The mere presence of pus draining from a pericardial tube represents $100 \%$ sensitivity to bacterial purulent pericarditis. After immediate pericardiocentesis, the fluid should be sent for extensive testing including cell count with differential, gram stain, acid-fast bacillus stain, fungal stain, and culture for both aerobic and anaerobic bacteria. Moreover, performing biochemical analysis can help distinguish between transudates and exudates. Fluid from bacterial pericarditis will reveal a high white blood cell count with predominance of polymorphonuclear cells, low glucose, high protein, and lactate dehydrogenase levels $[4,20,32,33]$. In our patient, the pericardial fluid that was yielded with the pericardiocentesis was milky or pussy, the sugar was relatively low, and the proteins were elevated. We know, however, that the pericardial fluid that is usually associated with the viral illnesses or rheumatological diseases is usually serous or serosanguinous. The blood WBC count was elevated with a left shift. These findings are most likely suggestive of a bacterial etiology of the pericardial effusion. The WBC was relatively lower than expected in bacterial pericarditis but this is not surprising since this bacterium is pauci-inflammatory in nature. Pericardioscopy and pericardial biopsy can be performed to increase the diagnostic accuracy [6]. As for diagnosing $C$. acnes specifically, it has various characteristics that make the diagnosis challenging. It is a common skin organism and it is frequently dismissed by physicians as a skin flora contaminant. It may also be missed when fluid culture is not incubated for a long time. And as such, it is both underdiagnosed and underreported [13, 34]. After consultation with our infectious diseases department regarding the management of our patient, we believe that his infection with $C$. acnes and its causal relationship to the development of pericardial effusion was genuine. The fluid cytology was indicative of a bacterial infection, fluid culture revealed $C$. acnes growth after 8 days of incubation, other testing for fungi and tuberculosis was negative, and the residual rim of effusion fully responded to antibiotics and disappeared. For future patients, it would have been helpful to culture the skin from areas such as the back, neck, underarms, and shoulder for growth and/or colonization of this organism. We did not perform this on our patient, but it might have added insight into the origin of $P$. acnes and its route to cause infectious pericarditis. We believe that this organism was the most likely cause of pericarditis in our patient. We acknowledge that it may be difficult to agree with this diagnosis as it is extremely rare. He received three weeks of IV antibiotics and follow-up revealed a residual rim of effusion, so he was given 3 weeks of oral antibiotics. The total 6-week duration of antibiotics points to the fact that there truly is a bacterial infection causing the pericarditis, one that responds to penicillin. The culture failed to grow any other organism, so we believe that Cutibacterium acnes is the most likely cause for the pericarditis.

4.5. Prognosis. The mortality of purulent bacterial pericarditis reaches $100 \%$ without timely and effective antimicrobial therapy. Even in patients who receive treatment, the mortality approaches $40 \%$. The serious complications that are associated with it are subsequent constrictive pericarditis 
and cardiac tamponade both of which can cause hemodynamic compromise. Other reported complications consist of aortic mycotic aneurysm, left ventricular pseudoaneurysm, and submitral pseudoaneurysm [3-5, 35-37]. Features that constitute poor prognosis include a delay in diagnosis, failure to initiate treatment, and an immunocompromised status. Proper investigation and timely administration of antibiotics have been shown to prevent several complications $[1,3]$.

4.6. Medical Management. In patients who present with hemodynamic compromise, prompt drainage and placement of a catheter are critical. Antibacterial therapy must be initiated immediately after diagnosis followed by sensitivityspecific medications. Intravenous antibiotics can achieve high concentrations in the pericardial effusion with a peak reaching approximately 2 hours after infusion [38]. The majority of Cutibacterium species are susceptible to carbapenems, penicillin, cephalosporins, vancomycin, and aminoglycosides. Expert opinion recommends initiating penicillin $G$ until the treatment can be further guided by antimicrobial susceptibility. Alternatively, combining an antistaphylococcal and an aminoglycoside can be started followed by a tailored therapy. If the infection is critical and life-threatening, a three-drug combination of vancomycin, third-generation cephalosporin, and fluoroquinolone can be given [39]. Metronidazole is the only agent to which C. acnes is consistently resistant and should be avoided. Other antibiotics with a relatively higher levels of resistance are clindamycin, erythromycin, and tetracycline [40]. There is no consensus on the required duration of antimicrobial treatment for C. acnes but is expected to be prolonged as this organism is intracellular and resists phagocytosis. A minimum of 4 weeks is recommended and should be extended to months in patients who recur $[1,2,4,12]$.

The pericardial space is bordered by the visceral and the fibrous layers. Regardless of the causative agent, whether infectious or postoperatively, inflammation of these layers increases fluid exudate. Inflammation also decreases the normal process of pericardial drainage by the lymphatic ducts. As such, inflammation alone can cause pericardial effusion and the use of nonsteroidal anti-inflammatory drugs (NSAIDs) and colchicine has been the cornerstone in the treatment of patients with acute or recurrent viral or idiopathic pericarditis. That being the case, we cannot exclude the presence of mere inflammation in the pericardial tissue in patients with pyogenic pericarditis [41, 42]. While NSAIDs have been historically used in idiopathic and viral pericarditis, we have shown that their use, in addition to targeted antibacterial therapy, in pyogenic pericarditis can provide benefit to the patients and hasten their recovery [43].

There is considerable evidence that supports the use of colchicine in patients with pericarditis to improve remission rates and reduce recurrence rates when used adjunctly with NSAIDs compared to NSAIDs alone. Colchicine concentrates inside granulocytes whose proinflammatory molecules are inhibited by its actions. In addition, it blocks the tubulin polymerization and impairs microtubule assembly, further contributing to decreased inflammation $[43,44]$. In a recent meta-analysis assessing different medical therapies for pericarditis, colchicine added to NSAIDs was associated with a reduced risk of treatment failure (OR, 0.23; 95\% CI, 0.11-0.49) and recurrent pericarditis (OR, 0.39; 95\% CI, 0.20-0.77) when compared to NSAIDs alone [45]. Another meta-analysis reported that the use of colchicine reduced risk of postpericardiotomy syndrome (OR, 0.48; 95\% CI, $0.33-0.68)$ and recurrent pericarditis in patients with acute pericarditis (OR, 0.31; 95\% CI, 0.19-0.52) [46].

In addition to antibiotics and anti-inflammatory drugs, the infusion of fibrinolytics has shown benefit in patients with fibropurulent pericarditis. Streptokinase or urokinase given intrapericardially can stop the drainage and decrease the risk of recurrence as well as complications. Adding corticosteroids to fibrinolytics has also been described as an alternative to surgical options [35, 41, 47, 48].

4.7. Surgical Management. Pericardial drainage is almost always indicated in patients who have massive pericardial effusion or in patients with small effusion not responsive to medical treatment. In addition, pericardial fluid drainage allows fluid cytology and analysis to be performed to identify the cause of the effusion. Other indications include the desire to administer a medication or drug into the pericardium [49]. In our patient, immediate pericardial drainage allowed 1.2 L of yellow fluid to be drained. However, the pericardial drain was not left in place for continuous drainage. After drainage, a repeat echocardiogram revealed only minimal residual pericardial effusion with normalization of vital signs and resolution of symptoms. As such, we were not prompted to keep a pericardial drain longer than medically necessary. In some cases, it may be medically indicated to keep a pericardial drain in the pericardium after evacuation of the fluid. If pericardiocentesis does not completely evacuate the fluid or if active secretion of fluid or bleeding is present and causes rapid reaccumulation of the effusion, then keeping a pericardial drain for a longer duration would be indicated. Continuous drainage of the pericardium is also necessary when more than $50 \mathrm{cc}$ of fluid remains in the pericardium after fluid evacuation. Nonetheless, the catheter should be removed as soon as possible in order to minimize the risk of infection [50, 51]. Often, the above-mentioned approach does not properly eradicate the infection especially in cases where fibrin accumulation may lead to a pericardial empyema, constrictive pericarditis, persistent infection, or tamponade recurrence. In these cases, extensive pericardiectomy or pericardial window may be necessary. It is estimated that $40 \%$ of patients with bacterial pericarditis resort to surgical interventions for complete resolution $[4,52]$. Immediate pericardiocentesis is life-saving but complete drainage is best achieved by surgical resection of the pericardium [20,33]. Controversy is present regarding the best surgical approach. Several surgical options exist such as placement of a pericardial window with pleural drainage, subxiphoid tube drainage, partial pericardiectomy with pericardial drainage, and total pericardiectomy. 
Subxiphoid pericardiotomy allows the surgeon to manually remove adhesions while establishing a pericardial window $[1,20,53]$. Selection of the best technique is multifactorial and depends primarily on the cause of pericarditis, fluid viscosity, clinical improvement after medical management, and the experience of the surgeon. Combining both medical and surgical approaches decreases mortality well below $20 \%$ $[4,52]$. We believe that early diagnosis and prompt medical therapy in our patient played an important role in the resolution of the pericarditis and his symptoms without resorting to a surgical intervention.

\section{Conclusion}

Bacterial pericarditis is a serious diagnosis that requires prompt diagnosis and treatment to avoid fatal complications. Pericarditis caused by Cutibacterium acnes is widely underreported. Isolation of this organism from pericardial fluid should not be disregarded as a skin contaminant especially in patients with a history of dental surgeries or implanted devices. The culture should be kept in the la for several days. Larger prospective studies are needed to examine the true incidence of $C$. acnes infection in patients presenting with pericardial effusion that have been otherwise misdiagnosed as idiopathic.

\section{Ethical Approval}

All human and animal studies have been approved by the appropriate ethics committee and have therefore been performed in accordance with the ethical standards laid down in the 1964 Declaration of Helsinki and its later amendments.

\section{Conflicts of Interest}

The authors declare that there are no conflicts of interest.

\section{References}

[1] F. Mookadam, S. E. Moustafa, Y. Sun et al., "Infectious pericarditis: an experience spanning a decade," Acta Cardiologica, vol. 64, no. 3, pp. 297-302, 2009.

[2] A. Farhat-Sabet, R. Hull, and D. Thomas, "Cardiac tamponade from purulent pericarditis due to Cutibacterium acnes," Case Reports in Cardiology, vol. 2018, Article ID 4739830, 5 pages, 2018.

[3] P. G. Klacsmann, B. H. Bulkley, and G. M. Hutchins, "The changed spectrum of purulent pericarditis," The American Journal of Medicine, vol. 63, no. 5, pp. 666-673, 1977.

[4] S. V. Parikh, N. Memon, M. Echols, J. Shah, D. K. McGuire, and E. C. Keeley, "Purulent pericarditis," Medicine, vol. 88, no. 1, pp. 52-65, 2009.

[5] J. Sagrista-Sauleda, J. Angel, A. Sambola et al., "Low-pressure cardiac tamponade: clinical and hemodynamic profile," Circulation, vol. 114, pp. 945-952, 2006.

[6] J. Sagristà-Sauleda, J. A. Barrabés, G. Permanyer-Miralda, and J. Soler-Soler, "Purulent pericarditis: review of a 20-year experience in a general hospital," Journal of the American College of Cardiology, vol. 22, no. 6, pp. 1661-1665, 1993.
[7] R. C. Cabot, R. E. Scully, J. Eugene et al., "Case records of the Massachusetts General Hospital. Weekly clinicopathological exercises. Case 23-1992. A 55-year-old man with recurrent pericardial and pleural effusions after aortic-valve replacement," New England Journal of Medicine, vol. 326, pp. 1550-1557, 1992.

[8] S. M. Horner, M. F. Sturridge, and R. H. Swanton, "Propionibacterium acnes causing an aortic root abscess," Heart, vol. 68, no. 8, pp. 218-220, 1992.

[9] J. M. Lazar and D. S. Schulman, "Propionibacterium acnesprosthetic valve endocarditis: a case of severe aortic insufficiency," Clinical Cardiology, vol. 15, no. 4, pp. 299-300, 1992.

[10] S. A. Niazi, D. Clarke, T. Do, S. C. Gilbert, F. Mannocci, and D. Beighton, "Propionibacterium acnes and staphylococcus epidermidis isolated from refractory endodontic lesions are opportunistic pathogens," Journal of Clinical Microbiology, vol. 48 , no. 11, pp. 3859-3869, 2010.

[11] D. Mesado, C. Sarriá, J. Bustamante, J. E. Rodríguez, L. Domínguez, and M. J. Olivera, "Constrictive infectious pericarditis caused by Propionibacterium acnes," Revista Española de Cardiología (English Edition), vol. 66, no. 5, pp. 407-409, 2013.

[12] D. Cruz, H. Ahmed, Y. Gandapur, and M. R. Abraham, "Propionibacterium acnes: a treatable cause of constrictive pericarditis," Case Reports in Medicine, vol. 2015, Article ID 193272, 3 pages, 2015.

[13] A. Perry and P. Lambert, "Propionibacterium acnes: infection beyond the skin," Expert Review of Anti-infective Therapy, vol. 9, no. 12, pp. 1149-1156, 2011.

[14] S. Delgado, A. Suárez, and B. Mayo, "Identification, typing and characterisation of Propionibacterium strains from healthy mucosa of the human stomach," International Journal of Food Microbiology, vol. 149, no. 1, pp. 65-72, 2011.

[15] Y. Achermann, E. J. C. Goldstein, T. Coenye, and M. E. Shirtliff, "Propionibacterium acnes: from commensal to opportunistic biofilm-associated implant pathogen," Clinical Microbiology Reviews, vol. 27, no. 3, pp. 419-440, 2014.

[16] J.-Y. Choi, M. S. Piao, J.-B. Lee, J. S. Oh, I.-G. Kim, and S.-C. Lee, "Propionibacterium acnes stimulates pro-matrix metalloproteinase-2 expression through tumor necrosis factor- $\alpha$ in human dermal fibroblasts," Journal of Investigative Dermatology, vol. 128, no. 4, pp. 846-854, 2008.

[17] J. J. Clayton, W. Baig, G. W. Reynolds, and J. A. T. Sandoe, "Endocarditis caused by Propionibacterium species: a report of three cases and a review of clinical features and diagnostic difficulties," Journal of Medical Microbiology, vol. 55, no. 8, pp. 981-987, 2006.

[18] A. H. Mohsen, A. Price, E. Ridgway, J. N West, S Green, and M. W McKendrick, "Propionibacterium acnes endocarditis in a native valve complicated by intraventricular abscess: a case report and review," Scandinavian Journal of Infectious Diseases, vol. 33, no. 5, pp. 379-380, 2001.

[19] H. Brüggemann, "Insights in the pathogenic potential of Propionibacterium acnes from its complete genome," Seminars in Cutaneous Medicine and Surgery, vol. 24, no. 2, pp. 67-72, 2005.

[20] S. Pankuweit, A. D. Risti, P. M. Seferovi, and B. Maisch, "Bacterial pericarditis," American Journal of Cardiovascular Drugs, vol. 5, no. 2, pp. 103-112, 2005.

[21] E. I. T. Sihvo, J. V. Räsänen, M. Hynninen, T. K. Rantanen, and J. A. Salo, "Gastropericardial fistula, purulent pericarditis, and cardiac tamponade after laparoscopic Nissen fundoplication," The Annals of Thoracic Surgery, vol. 81, no. 1, pp. 356-358, 2006. 
[22] J. H. Mitchell, M. C. Fraizer, L. A. Thet et al., "Purulent pericarditis induced by endobronchial needle injection of adenoviral-mediated gene therapy," The Canadian Journal of Cardiology, vol. 19, pp. 1421-1423, 2003.

[23] S. Gupta, K. Thompson, and L. Grellier, "Purulent pericarditis: a complication of endoscopic oesophageal variceal sclerotherapy," Endoscopy, vol. 37, no. 7, p. 688, 2005.

[24] H. J. Park, S. Na, S. Y. Park et al., "Clinical significance of Propionibacterium acnes recovered from blood cultures: analysis of 524 episodes," Journal of Clinical Microbiology, vol. 49, no. 4, pp. 1598-1601, 2011.

[25] J. R. Wilson and A. P. Limaye, "Risk factors for mortality in patients with anaerobic bacteremia," European Journal of Clinical Microbiology \& Infectious Diseases: Official Publication of the European Society of Clinical Microbiology, vol. 23, no. 4, pp. 310-316, 2004.

[26] M. E. Portillo, S. Corvec, O. Borens, and A. Trampuz, "Propionibacterium acnes: an underestimated pathogen in implant-associated infections," BioMed Research International, vol. 2013, Article ID 804391, 10 pages, 2013.

[27] J. M. Banzon, S. J. Rehm, S. M. Gordon, S. T. Hussain, G. B. Pettersson, and N. K. Shrestha, "Propionibacterium acnes endocarditis: a case series," Clinical Microbiology and Infection, vol. 23, no. 6, pp. 396-399, 2017.

[28] P. Y. Lee, M. J. Martin, and T. Treasure, "Propionibacterium acnes causing perivalve abscess," Heart, vol. 69 , no. 5, p. 470, 1993.

[29] T. T. Huynh, A. D. Walling, M. A. Miller, T. K Leung, Y Leclerc, and L Dragtakis, "Propionibacterium acnes endocarditis," The Canadian Journal of Cardiology, vol. 11, no. 9, pp. 785-787, 1995.

[30] H. Günthard, A. Hany, M. Turina, and J. Wüst, "Propionibacterium acnes as a cause of aggressive aortic valve endocarditis and importance of tissue grinding: case report and review," Journal of Clinical Microbiology, vol. 32, no. 12, pp. 3043-3045, 1994.

[31] A. A. Gharamti and Z. A. Kanafani, "Cutibacterium (formerly Propionibacterium) acnes infections associated with implantable devices," Expert Review of Anti-infective Therapy, vol. 15, no. 12, pp. 1083-1094, 2017.

[32] C. A. Kauffman, C. Watanakunakorn, and J. P. Phair, "Purulent pneumococcal pericarditis," The American Journal of Medicine, vol. 54, no. 6, pp. 743-750, 1973.

[33] A. A. Majid and A. Omar, "Diagnosis and management of purulent pericarditis," The Journal of Thoracic and Cardiovascular Surgery, vol. 102, no. 3, pp. 413-417, 1991.

[34] S.-C. Pan, J.-T. Wang, P.-R. Hsueh, and S.-C. Chang, "Endocarditis caused by Propionibacterium acnes: an easily ignored pathogen," Journal of Infection, vol. 51, no. 4, pp. e229-e231, 2005.

[35] D. Wright, J. Macmurray, M. Rothman et al., "Conditions of freedom," The Philosophical Quarterly, vol. 1, no. 3, pp. 286-298, 1951.

[36] S. Patel, R. Maves, C. P. Barrozo et al., "Mycotic pseudoaneurysm and purulent pericarditis attributable to methicillinResistantStaphylococcus aureus," Military Medicine, vol. 171, no. 8, pp. 784-787, 2006.

[37] A. d. N. Moraes, A. G. Ferreira Jr., and S. M. A. G. Ferreira, "Left ventricular pseudoaneurysm complicating infective pericarditis," Heart, vol. 82, no. 3, pp. 393-394, 1999.

[38] A. R. Martineau, N. J. Beeching, F. J. Nye, J. Croall, and A. A. Amadi, "Serum and pericardial fluid bactericidal assays in a patient with staphylococcal pericarditis," Journal of Infection, vol. 43, no. 2, pp. 158-159, 2001.
[39] C. Oprica and C. E. Nord, "European surveillance study on the antibiotic susceptibility of Propionibacterium acnes," Clinical Microbiology and Infection, vol. 11, no. 3, pp. 204-213, 2005.

[40] E. A. Eady, M. Gloor, and J. J. Leyden, "Propionibacterium acnes resistance: a worldwide problem," Dermatology, vol. 206, no. 1, pp. 54-56, 2003.

[41] B. Maisch, P. M. Seferovic, A. D. Ristic et al., "Guidelines on the diagnosis and management of pericardial diseases executive summary; the Task force on the diagnosis and management of pericardial diseases of the European society of cardiology," European Heart Journal, vol. 25, pp. 587-610, 2004.

[42] J. Sagristà-Sauleda, A. S. Merce, and J. Soler-Soler, "Diagnosis and management of pericardial effusion," World Journal of Cardiology, vol. 3, no. 5, pp. 135-143, 2011.

[43] M. Imazio, F. Gaita, and M. LeWinter, "Evaluation and treatment of pericarditis," JAMA, vol. 314, no. 14 , pp. 1498-1506, 2015.

[44] M. Imazio, A. Brucato, R. Cemin et al., "A randomized trial of colchicine for acute pericarditis," New England Journal of Medicine, vol. 369, no. 16, pp. 1522-1528, 2013.

[45] M. Lotrionte, G. Biondi-Zoccai, M. Imazio et al., "International collaborative systematic review of controlled clinical trials on pharmacologic treatments for acute pericarditis and its recurrences," American Heart Journal, vol. 160, no. 4, pp. $662-670,2010$.

[46] S. Alabed, J. B. Cabello, G. J. Irving, M. Qintar, and A. Burls, "Colchicine for pericarditis," Cochrane Database of Systematic Reviews, vol. 101, no. 18, 2014.

[47] M. Schafer, M. Lepori, A. Delabays, P. Ruchat, M. D. Schaller, and A. F. Broccard, "Intrapericardial urokinase irrigation and systemic corticosteroids: an alternative to pericardectomy for persistent fibrino-purulent pericarditis," Cardiovascular Surgery, vol. 10, no. 5, pp. 508-511, 2002.

[48] W.-B. Winkler, R. Karnik, and J. Slany, "Treatment of exudative fibririous pericarditis with intrapericardial urokinase," The Lancet, vol. 344, no. 8936, pp. 1541-1542, 1994.

[49] J. Sinisalo and J. Gunn, "Pericardial drainage and sampling," Duodecim, vol. 133, pp. 417-423, 2017.

[50] C. C. De Carlini and S. Maggiolini, "Pericardiocentesis in cardiac tamponade: indications and practical aspects," European Society of Cardiology, vol. 15, 2017.

[51] A. M. Rafique, N. Patel, S. Biner et al., "Frequency of recurrence of pericardial tamponade in patients with extended versus nonextended pericardial catheter drainage," The American Journal of Cardiology, vol. 108, no. 12, pp. 18201825, 2011.

[52] H. B. Cui, X. Y. Chen, C. C. Cui et al., "Prevention of pericardial constriction by transcatheter intrapericardial fibrinolysis with urokinase," Chinese Medical Sciences Journal=Chung-Kuo I Hsueh K'o Hsueh Tsa Chih, vol. 20, no. 1, pp. 5-10, 2005.

[53] A. Campione, M. Cacchiarelli, C. Ghiribelli et al., "Which treatment in pericardial effusion?" Journal of Cardiovascular Surgery, vol. 43, pp. 735-739, 2002. 